\title{
Mask Utilization: Knowledge, Attitude and Practice of Addis Ababa Dwellers on Usage of Different Masks in Combating COVID 19 Pandemic
}

\author{
Temesgen Kassa Getahun \\ Ethiopian Institute of Agricultural Research, Holeta Agricultural Research Centre, Holeta, Ethiopia
}

\section{Email address:}

Temesgen.kassa@eiar.gov.et

\section{To cite this article:}

Temesgen Kassa Getahun. Mask Utilization: Knowledge, Attitude and Practice of Addis Ababa Dwellers on Usage of Different Masks in Combating COVID 19 Pandemic. American Journal of Health Research. Vol. 9, No. 4, 2021, pp. 100-106. doi: 10.11648/j.ajhr.20210904.11

Received: April 14, 2021; Accepted: June 23, 2021; Published: June 30, 2021

\begin{abstract}
For the prevention of respiratory infection like the current pandemic COVID 19, face masks were considered as an effective method. To identify the gaps and immediate intervention of those gaps knowledge, attitude, and practice assessment of inhabitant on face mask utilization is very important to control the spread of the infection. Hence, the main aim of this study was to determine the dwellers knowledge, attitude, and practice of proper face mask utilization and associated factors at Kolfe Keranyo Subu City in Addis Ababa, Ethiopia. Across sectional study was conducted from 01/02/2021 to 10/03/2021 GC. The study covered 160 dwellers living in Kolfe Keranyo Sub City Woreda 08 Addis Ababa, Ethiopia. Pre-tested self-administered questionnaire were used to collect information from inhabitant after getting consent from the study participants. The data were collected, entered in to Microsoft excel 2010 and analyzed using R. software version 4.0. The association between predictor and outcome variables was measured using a logistic regression model. Statistical significance was declared at $p$-value $<0.05$. The study showed that $72(54 \%)$ of the respondents had Excellent knowledge, $136(85 \%)$ had positive attitude and $160(100 \%)$ of them had been practiced cloth face mask. All the 23 (14.4\%) of respondents who had practiced N 95 face mask have excellent knowledge on its utilization. From those who use cloth face mask, $24(15 \%)$ had negative attitude towards is use. Practically $52.5 \%$ of respondents had good practice on face mask utilization. According to the study, the knowledge level and attitude towards face mask utilization was relatively good, and the level of proper face mask utilization was also good. Consecutive training about a face mask and its proper utilization should be designed and given by the authorities to vulnerable peoples and to all the dwellers.
\end{abstract}

Keywords: Knowledge, Attitude, Practices, Proper Face Mask Utilization

\section{Background}

Emerging and reemerging infections have emerged as a threat to human health in recent decades [1]. The world is in the midst of the COVID-19 pandemic, which is caused by the SARS-CoV-2 virus. Lockdowns and travel restrictions imposed to halt the spread of COVID-19 have led to devastating economic repercussions. The control of an infectious disease is based on knowledge of its mode of transmission. The recent COVID-19 pandemic is caused by the novel coronavirus, SARS-CoV-2, which is transmitted largely by the respiratory route (vide infra) [2].

In December 2019, transmission of the novel coronavirus (SARS CoV-2) that causes coronavirus disease 2019 (COVID-19) discovered in Wuhan, China were known from person to person. Face masks are a type of personal protective equipment used to prevent the spread of respiratory infections, and it may be effective at helping prevent transmission of respiratory viruses and bacteria [3].

Different mask types were used to prevent COVID 19 transmission. A mask that is intended to be worn by health professionals in their work during medical procedures is known as surgical mask, also known as a medical face mask [4]. Thay use surgical face mask to prevent diseases transmitted by aerosol from infected patients and the treating personnel, by blocking the transmission of pathogens (primarily bacteria and viruses) shed in respiratory droplets and aerosols from the wearer's mouth and nose $[5,6]$. Surgical face mask cannot fully protect from small air born droplets that contain airborne bacteria or viruses, but could 
be still protective by filtering out and trapping most of the droplets that carry them. Evidences indicated that surgical masks can protect both the wearer and persons near the wearer from the spreading of viruses $[7,8]$.

A surgical mask, by design, does not filter or block very small particles in the air that may be transmitted by coughs, sneezes, or certain medical procedures. Surgical masks also do not provide complete protection from germs and other contaminants because of the loose fit between the surface of the face mask and the face [9]. If worn properly, a surgical mask is meant to help block large-particle droplets, splashes, sprays, or splatter that may contain viruses and bacteria, keeping it from reaching the wearer's mouth and nose [9]. Surgical masks are effective barriers for retaining large droplets released from the mouth and nose by the wearer in public [2]. Surgical masks help reduce exposure of the wearer's saliva and respiratory secretions to others that could otherwise travel up to 26 feet [10]. Surgical mask also remind wearers not to touch their mouth or nose, which could otherwise transfer viruses and bacteria after having touched a contaminated surface. Collection efficiency of surgical mask filters can range from less than $10 \%$ to nearly $90 \%$ for different manufacturers' masks [11].

A mask made of common textile mostly cotton, used to worn over the nose and mouth is a cloth face. It is recommended by public health when nationally ratified masks are not available, and when overcrowding for disease "source control" in epidemic. Cloth face mask is less effective than N95 and surgical masks. Public health agencies were not considered to be personal protective equipment. They are used in the societies in household and community settings as protection against both infectious diseases and particulate air pollution [12]. During the COVID-19 pandemic, their use in developed countries was revived due to shortages of surgical masks and respirators, as well as for environmental concerns and practicality [13].

An N95 filtering facemask respirator, commonly abbreviated N95 respirator [14] is a particulate-filtering facepiece respirator that meets the U.S. National Institute for Occupational Safety and Health (NIOSH) classification of air filtration, meaning that it filters at least $95 \%$ of airborne particles. The N95 type is the most common particulatefiltering face piece respirator [15]. The Occupational Safety and Health Administration (OSHA) of United State recommended N95 for healthcare workers who are expected to perform patient activities with those suspected or confirmed to be infected with COVID-19 [16]). The CDC also recommends the use of N95 face mask to protect the wearer from inhalation of infectious particles including TB, avian influenza, severe acute respiratory syndrome (SARS), pandemic influenza, and Ebola [17]. Unlike a respirator, a surgical mask does not have an air-tight seal and thus does not protect its wearer against airborne particles such as virus material to the same extent [16].

EN 149 is a mask that defines three different classes of masks, called FFP1, FFP2 and FFP3, (FFP = Filtering Face Piece) which classify according to their filtering efficiency
[18]. Those are used as mechanical filter respirators to protect against the inhalation of droplets that include particulates such as dust particles and aerosols. EN 149 FFP2 masks have similar performance requirements to N95 masks in the United States and KN95 filters of China, and EN 149 FFP3 masks have similar performance requirements to N99 masks in the United States. However EN 149 test requirements differ somewhat from the U. S. / Chinese / Japanese standards: EN 149 requires an additional paraffin-oil aerosol test and it tests at a range of different flow rates and defines several associated and permissible pressure drop levels [17]).

Currently in Ethiopia COVID 19 is highly spreading among the people especially in and around the capital city Addis Ababa. There is high intensification between peoples in public transport, public market and Hotels especially in capital city and zonal city. Ministry of Health exhaustively diagnoses suspected groups, vulnerable peoples and medical practitioners, people who had contact with infected peoples and immigrants. Farmers and low income peoples did not have deep awareness about the pandemic. Even though the disease is highly diffuse in the population, most of people in Addis Ababa did not use face mask properly currently. Therefore, this paper was carried out with the following objectives:

To assess knowledge, attitude and practice towards utilization different face mask available in Kolfe Keranyo Sub City Woreda 08, Addis Ababa, Ethiopia.

\section{Methods}

\subsection{Study Area}

This study was conducted in Kolfe Keranyo Sub City Woreda 08, Addis Ababa, Ethiopia. Kolfe Keranio, also spelled Kolfe Keraneo or simply Kolfe, is one of the 10 subcities of Addis Ababa, the capital of Ethiopia. As of 2011 its population was of 546,219 . The district is located in the western suburb of the city, near the Gefersa Reservoir. It borders with the districts of Gullele, Addis Ketema, Lideta and Nifas Silk-Lafto [19].

\subsection{Study Design}

A cross sectional study was conducted from 01/02/2021 to 10/04/2021. Respondent was selected randomly from different location for interview.

\subsection{Study Population}

The study population was of peoples found in different location of Kolfe Keranyo Sub City Woreda 08, Addis Ababa during the study period and who fulfill the inclusion criteria were the study population. The inclusion criteria for this study were those dwellers that were willing to give informed consent and available at the time of the study. A total of 160 respondents were randomly selected from different location of the study area.

\subsection{Data Collection}

Structured questioner was developed to assess the status, knowledge, attitude and practice of respondents on face mask 
in Addis Ababa. The questionnaire was developed by reviewing previous different literature on the type, proper use and the guidelines of the Centre for Health Protection WHO and the $\mathrm{CDC}$ [20] and in consultation with experts from different fields to check the relevance and make necessary changes according to the study requirements. The selfadministered questionnaire were developed contained different sections; basic demographic characteristics (age, gender, education status, job), knowledge-related questions, attitude related questions, and practice-related questions regarding the use of proper face mask utilization.

\subsection{Operational Definition and Its Measurements}

\subsubsection{Knowledge about Face Mask and Its Use}

For the convenience of analyses, each correct response in the knowledge category was scored 1, and each incorrect response was scored 0 . The final score was calculated and then labeled based on score. The correct response of questions $>90 \%$ excellent, $75-90 \%$ very good, $50-75 \%$ good and $<50 \%$ poor knowledge [20].

\subsubsection{The Attitude of Face Mask Utilization}

Respondents were asked four questions to describe their negative and positive attitude [20].

\subsubsection{Proper Practice of Face Mask Utilization}

For the convenience of analyses, each correct response in the practice category was scored 1 , and each incorrect response was scored 0 . The response of respondents was considered as good practice and considered as poor practice [20].

\subsection{Data Analysis}

An R-software version 4.0 package was used to analyze the data. Frequency and percent of given data for each variable were calculated. Summary statistics of given data for each variable were calculated. A logistic regression model was used to measure the association between the outcome like Knowledge attitude and practice of proper face mask utilization and the associated factors. Statistical significance was declared at $\mathrm{p}$-value $<0.05$.

\section{Result}

\subsection{Socio-Demographic Characteristics}

A total of 160 respondents from Kolfe Keranyo Sub City Woreda 8 Addis Ababa were included in this study. Around one-third of the study subjects, 69 (43.1\%) were adult. The majority of the respondent $87(54.4 \%)$ were males. The educational level of major respondents, 61 (38.1\%) were primary school (Table 1).

Table 1. Demographic characteristics of respondent.

\begin{tabular}{lll}
\hline Variable & No. of respondent & Percent (\%) \\
\hline Sex & & \\
Male & 73 & 45.6 \\
Female & 87 & 54.4 \\
Age & & \\
Children & 24 & 15 \\
Young & 49 & 30.6 \\
Adult & 69 & 43.1 \\
Old & 18 & 11.3 \\
Education status & & \\
Not read and write & 11 & 6.9 \\
Primary school & 61 & 38.1 \\
Secondary school & 26 & 16.3 \\
Preparatory school & 11 & 9 \\
Degree & 51 & 31.9 \\
Job & & \\
Jobless & 11 & 6.9 \\
Employee & 32 & 23.1 \\
Merchant & 66 & 41.3 \\
Student & 35 & 21.9 \\
Retire & 11 & 6.9 \\
\hline
\end{tabular}

\subsection{Face Mask Utilization Status}

Among respondents $81(50.6 \%)$ were responded that at the time of the study wear face mask sometimes only (Table 2). Majority of the respondents, 83 (51.9\%) of respondents were mostly use cloth face mask (Table 3 ). Cloth face mask were selected by most of the respondents due to its low cost while respondents who select N 95 were based on its high level of protection and easy to use (Table 4).

Table 2. Face mask utilization status of respondents.

\begin{tabular}{lll}
\hline Mask utilization status & No. of respondents & Percent (\%) \\
\hline Currently stop to use & 30 & 18.8 \\
Outside home only & 22 & 13.8 \\
Sometimes only & 81 & 50.6 \\
All time & 27 & 16.9 \\
\hline
\end{tabular}

Table 3. Type of mask mostly used by respondents.

\begin{tabular}{lll}
\hline Type of mask & No. of respondents & Percent \\
\hline Cloth face mask & 83 & 51.9 \\
N 95 & 23 & 14.4 \\
FFP & 1 & 0.6 \\
Surgical face mask & 53 & 33.1 \\
\hline
\end{tabular}

Table 4. Selection criteria for different facemask.

\begin{tabular}{|c|c|c|c|c|}
\hline Selection criteria & Cloth face mask (\%) & N 95 face mask (\%) & FFP face mask (\%) & Surgical face mask $(\%)$ \\
\hline Cost & $87(54.4)$ & 0 & 0 & $49(30.6)$ \\
\hline Level of protection & $24(15)$ & $23(13.4)$ & $1(0.6)$ & $27(16.9)$ \\
\hline Easy to use & $74(46.2)$ & $23(14.4)$ & $1(0.6)$ & $38(23.8)$ \\
\hline Cost and level of protection & $24(15)$ & 0 & 0 & $27(16.9)$ \\
\hline Cost and easy to use & $74(46.2)$ & 0 & 0 & $38(23.8)$ \\
\hline Level of protection and easy to use & $24(15)$ & $23(14.4)$ & $1(0.6)$ & $27(16.9)$ \\
\hline Cost, level of protection and easy to use & $24(15)$ & 0 & 0 & $27(16.9)$ \\
\hline
\end{tabular}


Out of 160 respondents 7 (4.4\%) were reported that they tested for COVID 19, out of which 2 (1.25\%) has been reported positive (recovered at the time of interview). Those test positive were merchants, currently stop to wear face mask and previously mostly use cloth face mask (Table 5).

Table 5. Multivariable regression of risk factors for COVID 19 infection.

\begin{tabular}{|c|c|c|c|c|c|}
\hline \multirow{2}{*}{ Variables } & \multicolumn{3}{|c|}{ COVID 19 test status } & \multirow{2}{*}{$X^{2}$-Value } & \multirow{2}{*}{ P-Value } \\
\hline & Not tested (\%) & Teste positive (\%) & Test negative (\%) & & \\
\hline Age & & & & 33.87 & 0.0003 \\
\hline Child & $24(15)$ & 0 & 0 & & \\
\hline Young & $49(30.6)$ & 0 & 0 & & \\
\hline Adult & $67(41.9)$ & $2(1.3)$ & $2(1.3)$ & & \\
\hline Old & $11(6.9)$ & 0 & 5 & & \\
\hline Sex & & & & 4.707 & 0.0872 \\
\hline Female & $72(45)$ & 0 & $1(0.6)$ & & \\
\hline Education status & & & & 6.947 & 0.534 \\
\hline Not read and write & $11(6.9)$ & 0 & 0 & & \\
\hline Primary school & $58(36.3)$ & $1(0.6)$ & $2(1.3)$ & & \\
\hline Secondary school & 52 & $1(0.6)$ & $3(1.9)$ & & \\
\hline Preparatory & $11(6.9)$ & & 0 & & \\
\hline Degree & $49(30.6)$ & 0 & $2(1.3)$ & & \\
\hline Student & $35(21.9)$ & 0 & 0 & & \\
\hline Merchant & $61(38.125)$ & $1(0.6)$ & $4(2.5)$ & & \\
\hline Employee & $33(20.6)$ & $1(0.6)$ & $3(1.9)$ & & \\
\hline Retire & $1(6.9)$ & 0 & 0 & & \\
\hline Mask use status & & & & 31.115 & 0.00013 \\
\hline All time & $27(16.9)$ & 0 & 0 & & \\
\hline Outside only & 22 & 0 & 0 & & \\
\hline Sometimes only & $80(50)$ & 0 & $1(0.6)$ & & \\
\hline Currently stop to use & $22(13.8)$ & $2(1.3)$ & 6 & & \\
\hline Type of mask mostly used & & & & 8.847 & 0.051 \\
\hline Cloth face mask & $72(45)$ & $2(1.3)$ & $7(4.4)$ & & \\
\hline Surgical face mask & $53(33.13)$ & 0 & 0 & & \\
\hline N 95 & $23(14.4)$ & 0 & 0 & & \\
\hline FFP & $1(0.6)$ & 0 & 0 & & \\
\hline
\end{tabular}

\subsection{KAP Assessment}

\subsubsection{Level of Knowledge}

Most of the respondents were well informed about different type of face masks available in the area. Of the total of 160 respondents, 72 (45\%) of them had excellent knowledge about face mask. About 25 (15.6\%), 23 (14.3\%), 23 (14.3) of respondents had excellent knowledge that surgical, N 95 and cloth face mask can protect from COVID19 respectively (Figure 1).

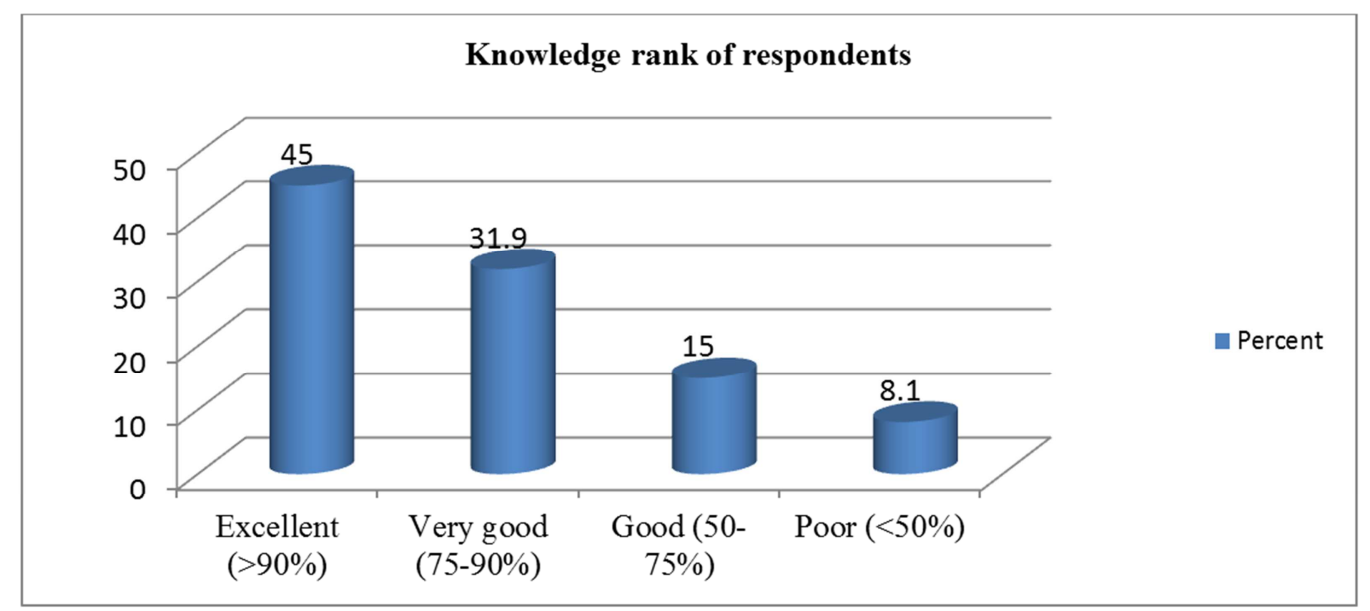

Figure 1. Assessment of respondent's knowledge on importance of face masks to protect COVID 19. 
Table 6. Multivariable regression of knowledge level of respondents against different factors.

\begin{tabular}{|c|c|c|c|c|c|c|}
\hline \multirow{2}{*}{ Variable } & \multicolumn{4}{|c|}{ Knowledge level } & \multirow{2}{*}{$X^{2}$-value } & \multirow{2}{*}{ P-value } \\
\hline & Excellent (\%) & V. $\operatorname{good}(\%)$ & Good (\%) & Poor (\%) & & \\
\hline Mask use status & & & & & 102.22 & 0.000 \\
\hline All time & $13(8.13)$ & $14(8.8)$ & 0 & 0 & & \\
\hline Outside only & $11(6.8)$ & $11(6.8)$ & 0 & 0 & & \\
\hline Sometimes only & 0 & $13(8.13)$ & $20(12.5)$ & $48(30)$ & & \\
\hline Currently stop to use & 0 & $20(12.5)$ & $4(2.5)$ & $26(16.3)$ & & \\
\hline Face mask type used & & & & & 57.214 & 0.000 \\
\hline Cloth & 23 & $26(16.3)$ & $22(13.8)$ & $12(7.5)$ & & \\
\hline Surgical & 25 & $25(15.6)$ & $1(0.6)$ & $2(1.3)$ & & \\
\hline N 95 & $23(14.4)$ & 0 & 0 & 0 & & \\
\hline FFP & $1(0.6)$ & 0 & 0 & 0 & & \\
\hline
\end{tabular}

\subsubsection{Attitude of the Respondents towards Face Mask Utilization}

Most of respondents, $136(85 \%)$ had a positive attitude towards face mask utilization (Figure 2). This study identified 24 (15) respondents had negative attitude to use cloth face mask, while $53(33.13 \%)$ and 23 (14.4\%) of them had positive attitude to use surgical and $\mathrm{N} 95$ face mask respectively (Table 7).

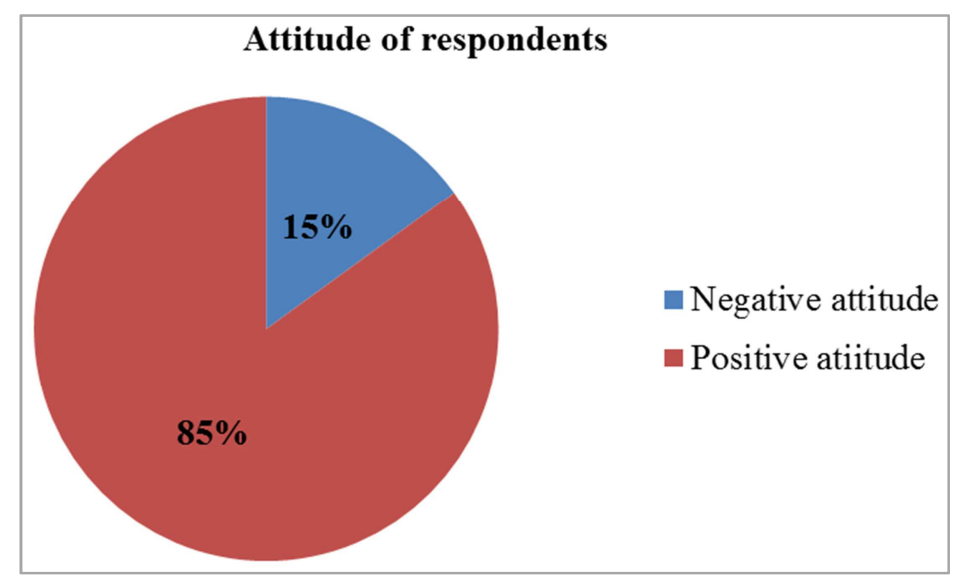

Figure 2. Assessment of respondent's attitude towards wearing of face mask to protect COVID 19.

Table 7. Attitude towards utilization of different face masks.

\begin{tabular}{lllll}
\hline \multirow{2}{*}{ Variable } & \multicolumn{2}{l}{ Attitude towards utilization of different face masks } & \multirow{2}{*}{$\mathbf{X}^{2}$-value } & \multirow{2}{*}{ P-value } \\
\cline { 2 - 3 } & Positive attitude (\%) & Negative attitude (\%) & 26.194 & 0.000 \\
\hline Face mask type used & $59(36.9)$ & $24(15)$ & & \\
Cloth & $53(33.13)$ & 0 & & \\
Surgical & $23(14.4)$ & 0 & & \\
N 95 & $1(0.6)$ & 0 & & \\
FFP & & 0 & & \\
\hline
\end{tabular}

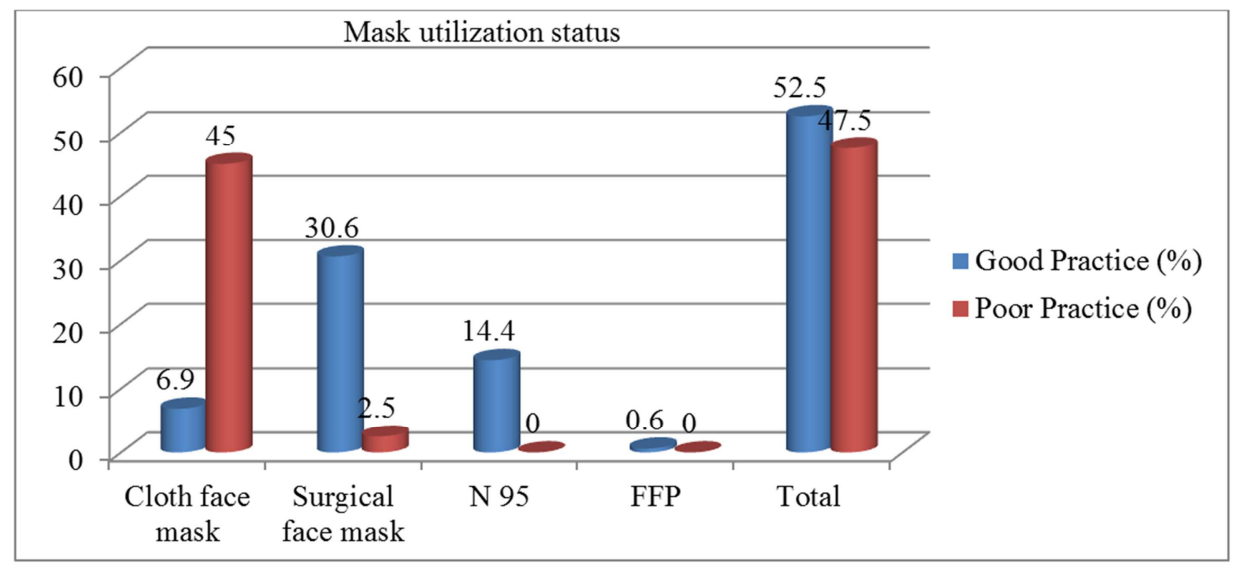

Figure 3. Mask utilization practice. 
Table 8. Practice on using different face masks.

\begin{tabular}{lll}
\hline Practice & No. of respondents & Percent \\
\hline Cloth face mask & 160 & 100 \\
Surgical face mask & 147 & 91.9 \\
N 95 & 84 & 52.5 \\
FFP & 13 & 8.1 \\
\hline
\end{tabular}

\subsubsection{Proper Practice of Face Mask Utilization of the Respondents}

All the respondents have been a practice of wearing cloth face mask (Table 8 ). Of the total of 160 respondents, 76 $(47.5 \%)$ of them had a poor practice of face mask utilization (Figure 3). Good practice of face mask use was higher among respondents who wear surgical and N 95 face mask (Figure 3).

\section{Discussion}

Wearing a face mask has numerous importance for the user. It will help to prevent the spread of infection from one person to others like COVID-19 [21]. So this study was conducted with the main aim of determining the knowledge attitude, practice, and associated factors of proper face mask utilization practice at Kolfe Keranyo Sub City woreda 8 of Addis Ababa Ethiopia.

A systematic review and meta-analysis conducted by different authors in different country to assess the efficacy of face mask in preventing respiratory virus transmission were showed that the proper use of masks by healthcare professionals and non-healthcare professional can reduce the risk of respiratory virus infection by $80 \%$ [22]. But the finding of the current study shows proper face mask utilization in the study area was $52.5 \%$. This finding is slightly gather than the study conducted at Dessie referral hospital which was reported as $35.1 \%$ of the health professionals were wore a face mask when handling TB suspected patients only [23] and with the study conducted in Pakistan which was 35.2 of the healthcare workers wear face mask correctly. The higher proper mask utilization in the study area may be due to awareness created by mass Medias and social Medias are high. In the other hand dwellers in the study area were more vulnerable so are forced to use face mask [24].

During the study time $30(18.8 \%)$ of the respondents reported that they were totally stop to wear any type of face mask in all situation. This finding is lower compared to the finding of the study conducted in Malaysia that reported as
$51.2 \%$ of the public had not used face mask [25]. Currently some people in the population forget the disease in the study area so that some peoples ignore face mask to use.

With regards to the attitude of respondents towards face mask utilization, in the current study, more than half $85 \%$ of the respondents had a positive attitude towards proper face mask utilization. This was much higher compared to the study conducted in Dessie Amhara Ethiopia which accounted for $76.4 \%$ of the health workers [23]. This difference might be due to the difference in study area and tool, and similarly, it was almost equal to the study done in Malaysian public which accounted 83.1 [25]. This similarity might be due to the adequate global awareness of the population on the efficiency of face mask on the prevention of respiratory illness like COVID-19.

The current study identified that $8.1 \%$ of the respondents had poor knowledge about face masks. The result was lower than the study conducted in Dessie, Ethiopia which in which $86.4 \%$ of them had good knowledge [23] and with the study conducted in Public Malaysia which accounted for $80.5 \%$ of the public participants were knowledgeable [25]. This difference might be contributed to the different study population sample size determination and operational definition.

\section{Conclusion and Recommendation}

This study identified the knowledge, attitude, and practice of proper face mask utilization among respondents in Kolfe Keranyo sub city A. A Ethiopia. Accordingly the knowledge of dwellers on face mask, attitude towards its importance and practice of respondents on proper face mask utilization was good. Age, job, mask use status and type of face mask mostly used were significantly associated with the corona virus infection. Consecutive training about a face mask and its proper utilization should be designed and given by the authorities to all the population. The concerned authorities should also design different policies and guidelines that should address the different types of face mask, their use, and the importance of proper use of face mask use during the COVID 19 pandemic.

\section{List of Abbreviations}

$\begin{array}{ll}\text { CCOHS } & \text { Canadian Centre for Occupational Health and Safety } \\ \text { CDC } & \text { center for disease control } \\ \text { CEN } & \text { European Committee for Standardization (CEN) } \\ \text { FDA } & \text { Food and Drug Administration } \\ \text { NIOSH } & \text { National Institute for Occupational Safety and Health }\end{array}$




\section{Declarations}

\section{Authors' Contributions}

All data collection, analysis and writing up were conducted by T Kassa.

All authors read and approved the final manuscript.

\section{Consent for Publication}

The owner gave informed consent for publication.

\section{Acknowledgements}

I would like to thank Gete Fikadu for devoting her time in editing language and technical aspects.

\section{References}

[1] Wong SY, Tan BH. Megatrends in infectious diseases: the next 10 to 15 years. Ann Acad Med Singapore. 2019; 48 (6): 188-94.

[2] CCOHS. Respiratory Protection Against Airborne Infectious Agents for Health Care Workers: Do surgical masks protect workers?" (OSH Answers Fact Sheets). Canadian Centre for Occupational Health and Safety. 28 February 2017. Retrieved 28 February 2017. Vol. 94, OSH. Elsevier; 2020.

[3] Guan W, Ni Z, Hu Y, Liang W, Ou C, He J, et al. Clinical characteristics of coronavirus disease 2019 in China. N Engl J Med. 2020; 382 (18): 1708-20.

[4] Smith JD, MacDougall CC, Johnstone J, Copes RA, Schwartz B, Garber GE. Effectiveness of N95 respirators versus surgical masks in protecting health care workers from acute respiratory infection: a systematic review and meta-analysis. Cmaj. 2016; 188 (8): 567-74.

[5] WHO. Prevention of hospital-acquired infections" (PDF). World Health Organization (WHO). p. 45. Archived (PDF) from the original on 26 March 2020. 2020; 69 (12): 347-52.

[6] WHO. Prevention of hospital-acquired infections" (PDF). World Health Organization (WHO). p. 45. Archived (PDF) from the original on 26 March 2020. (http://dx.doi.org/10.18203/2394-6040.ijcmph20164285).

[7] Sommerstein R, Fux CA, Vuichard-Gysin D, Abbas M, Marschall J, Balmelli $\mathrm{C}$, et al. Risk of SARS-CoV-2 transmission by aerosols, the rational use of masks, and protection of healthcare workers from COVID-19. Antimicrob Resist Infect Control. 2020; 9 (1): 1-8.

[8] Peeples L. Face masks: what the data say. Nature. 2020; 586 (7828): 186-9.

[9] FDA. N95 respirators and surgical masks (face masks). US Food Drug Adm. 2020.

[10] Padilla, Ramon; Zarracina J. Coronavirus might spread much farther than 6 feet in the air. CDC says wear a mask in public". USATODAY.com. Retrieved 4 April 2020. 2020.
[11] Tang JW, Nicolle ADG, Pantelic J, Jiang M, Sekhr C, Cheong DKW, et al. Qualitative real-time schlieren and shadowgraph imaging of human exhaled airflows: an aid to aerosol infection control. PLoS One. 2011; 6 (6): e21392.

[12] Shakya KM, Noyes A, Kallin R, Peltier RE. Evaluating the efficacy of cloth facemasks in reducing particulate matter exposure. J Expo Sci Environ Epidemiol. 2017; 27 (3): 352-7.

[13] CDC. Use of Cloth Face Coverings to Help Slow the Spread of COVID-19". U.S. Centers for Disease Control and Prevention. April 4, 2020. Retrieved April 5, 2020. This article incorporates text from this source, which is in the public domain. 2020.

[14] NIOSH. NIOSH-Approved N95 Particulate Filtering Facepiece Respirators, https://www.cdc.gov/niosh/npptl/topics/respirators/disp part/n 95listl-a.html. 2020.

[15] NIOSH. NIOSH_CDC. 2020.

[16] D’Alessandro MM, Cichowicz JK. Proper N95 Respirator Use for Respiratory Protection Preparedness. Centres Dis Control Prev https//blogs cdc gov/niosh-science-blog. 2020; (95).

[17] CDC. Guideline for isolation precautions: preventing transmission of infectious agents in healthcare settings. http//www cdc gov/hicpac/2007IP/2007isolationPrecautions html. 2019.

[18] TTS CCCcTS. Respiratory Protective Devices-Filtering Half Masks to Protect Against Particles-Requirements, Testing, Marking. 2020.

[19] Kolfe Keranio Archived. City Government of Addis Ababa. 2013.

[20] Kumar J, Katto MS, Siddiqui AA, Sahito B, Jamil M, Rasheed $\mathrm{N}$, et al. Knowledge, attitude, and practices of healthcare workers regarding the use of face mask to limit the spread of the new coronavirus disease (COVID-19). cureus. 2020; 12 (4).

[21] Organization WH. Advice on the use of masks in the community, during home care and in healthcare settings in the context of the novel coronavirus ( 2019-nCoV) outbreak: interim guidance, 29 January 2020. World Health Organization; 2020.

[22] Liang M, Gao L, Cheng C, Zhou Q, Uy JP, Heiner K, et al. Efficacy of face mask in preventing respiratory virus transmission: A systematic review and meta-analysis. Travel Med Infect Dis. 2020; 36: 101751.

[23] Gezie H, Leta E, Admasu F, Gedamu S, Dires A, Goshiye D. Health care workers knowledge, attitude and practice towards hospital acquired infection prevention at Dessie referral hospital. Northeast Ethiop. 2019.

[24] Geremew D, Endalamaw A, Negash M, Eshetie S, Tessema B. The protective effect of isoniazid preventive therapy on tuberculosis incidence among HIV positive patients receiving ART in Ethiopian settings: a meta-analysis. BMC Infect Dis. 2019; 19 (1): 1-9.

[25] Mohamad EMW, Azlan AA, Hamzah MR, Tham JS, Ayub SH. Public knowledge, attitudes and practices towards COVID-19: A cross-sectional study in Malaysia. medRxiv. 2020. 